\title{
Socio-economic Factors Affecting Monthly Household Expenditure on Tuition for Advanced Level Students in Embilipitiya Educational Zone in Sri Lanka
}

Sri Lanka Journal of Social Sciences and Humanities Volume 1 Issue 2, June 2021: 77-85 ISSN: $2773692 X$ (Online), 27736911 (Print) Copyright: (C) 2021 The Author(s) Published by Faculty of Social Sciences and Languages, Sabaragamuwa University of Sri Lanka Website: https://www.sab.ac.lk/sljssh DOI: http://doi.org/10.4038/sljssh.v1i2.40

\author{
Thilakasingha, A.S. ${ }^{1}$ and Fernando, M.A.C.S.S. ${ }^{1 *}$ \\ ${ }^{1}$ Department of Economics and Statistics, Sabaragamuwa University of Sri Lanka, Belihuloya, 70140, Sri Lanka.
}

Received: 29 November, 2020, Revised: 16 March, 2021, Accepted: 07 May, 2021.

How to Cite this Article: Thilakasingha, A.S., and Fernando, M.A.C.S.S. (2021). Socio-economic factors affecting monthly household expenditure on tuition for advanced level students in Embilipitiya educational zone in Sri Lanka. Sri Lanka Journal of Social Sciences and Humanities, 1(2), 77-85.

\begin{abstract}
School education as well as university education (up to undergraduate level) is mostly government-owned and free in Sri Lanka. However, the General Certificate of Education Advanced Level (G.C.E A/L) Examination has become a huge challenge for students as this is the only eligibility criterion for university entrance which is extremely competitive. Consequently, parents increasingly spend on getting private tuition for their children. This study investigates the socio-economic factors affecting monthly household expenditure on A/L students' tuition. A stratified random sample of 200 out of 1160 students who sat for the $A / L$ examination in 2019 in each subject stream: Arts, Biological Science, Commerce, Physical Science, and Technology in Embilipitiya educational zone of Rathnapura district in Sri Lanka was selected for the study. Based on the current literature and the Sri Lankan context related to the area of research, 11 factors were identified as the potential determinants of monthly tuition expenditure of Advanced Level students. Data were collected using a structured questionnaire. The multiple linear regression analysis performed in the study revealed that household income, total tuition hours, type of class, and subject stream are the major factors determining the monthly expenditure on private tuition classes. The finalized regression model including the above factors explains more than $71 \%$ of the variation in monthly tuition expenditure. Furthermore, the highest and the lowest median monthly tuition expenditures were observed for the students from Physical Science and Arts streams respectively. The findings of this research provide important insights to educators and policymakers while extending the limited current knowledge on private tuition in Sri Lanka.
\end{abstract}

Keywords: Multiple linear regression, Prediction, Private tuition, Socio-economic factors, Tuition expenditure

\section{INTRODUCTION}

Education expenditure is receiving much attention from education policymakers as it accounts for a significant portion of household expenditure, especially in Asian countries. Sri Lanka is a South Asian country where school education, as well as university education (up to undergraduate level), is mostly government-owned and free. However, it is debatable for many years whether this education is free because of the widespread private schools, universities, and tuition classes (Cole, 2016). As both government and private school children go for tuition, currently it seems to be a major category of education expense of households. The performance in the General Certificate of Education Advanced Level (G.C.E. A/L) Examination is the only eligibility criterion for entering a national university in Sri Lanka. Due to extremely high cut-off Z-scores and small intakes for many degree programs, university entrance has become a dream goal for most of the youth in Sri Lanka. Consequently, a massive competition has been created among the Advanced Level students. The uneven distribution of education facilities and low satisfaction about the level of quality of school education motivates students to obtain private tuition. Under the present circumstances, private tuition in Sri Lanka is a fashion than a requirement on which many families tend to spend a lot of their monthly expenditure. Various social and economic factors can affect the amount of expenditure on $\mathrm{A} / \mathrm{L}$ private tuition. Identification of these factors and understanding their impact will be particularly useful for government and non-government educational institutions in planning secondary and tertiary education programs and introducing suitable solutions for the existing problems in the local education system. Therefore, this study aims to:

1. identify the key socio-economic factors that are directly influencing monthly household expenditure on private tuition for A/L students in Sri Lanka and

2. to evaluate the magnitude of the impact of each factor.

As previous research on patterns of private tuition expenditure and their influencing factors were mostly descriptive and/or limited to small samples or countries other than Sri Lanka, this study attempts to explore empirical findings related to the above topic using a sample of $200 \mathrm{~A} / \mathrm{L}$ students,

\footnotetext{
* Corresponding author: Tel.: +94(71)8099101; Email: sampathf@ssl.sab.ac.lk (iD) https://orcid.org/0000-0003-4881-388X
} 
which represents $17 \%$ of the target population of Embilipitiya educational zone of Rathnapura district in Sri Lanka.

\section{LITERATURE REVIEW}

Private tuition is widespread in developing countries such as Sri Lanka, Bangladesh, Vietnam, as well as in some developed countries such as Japan, USA, UK, and South Korea (Pallegedara, 2012). Researchers have identified this as a serious educational issue that can make free education policy in Sri Lanka useless and widen the gap in educational equality (Cole, 2016; Pallegedara, 2012). However, not only the negative but also positive effects of private supplementary tutoring have been highlighted in the literature (Bray \& Lykins, 2012). The identified negative effects are: threatened social cohesion due to different abilities of families at different income levels to pay for tuition and to receive a quality education; deliberately reduced efforts of teachers devoted to regular teaching in schools because of their engagement in private tutoring; reducing time for sports and other activities that help children's balanced and healthy life; low effectiveness because the tutors are not trained properly; and unguaranteed quality as the tutoring is poorly supervised and inadequately regulated. However, tuition may help students to keep up with peers and achieve high levels of performance, get extra learning that may contribute human capital for economic development, and reduce the spare time of adolescents that may otherwise lead them to wrong ends.

Sri Lanka Education Reports (2007) identifies four reasons for attending private tuition classes. These are: high competition, lack of knowledge of parents, insufficient time to cover the syllabus in schools, and the poor teacher-student relationship. Tutorials that consist of examination-oriented questions have become another influential factor that motivates students for private tuition classes (National Education Research and Evaluation Center, 2004). Attendance of the students at schools is very poor as many of the tuition classes for $\mathrm{A} / \mathrm{L}$ students are conducted during school time. As many private tuition class teachers in Sri Lanka are school teachers, attending private tuition classes has been considered by students as an essential element of education (Educational Social Science Foundation, 1989). Supporting this argument, Pallegedara (2012) found that private tutoring expenditure has changed from that of a luxury good in 19951996 to a necessary good in 2006-2007.

There are various socio-economic factors that could affect the amount of tuition expenses of a family. In Sri Lanka, these factors can be largely varied from those that have been considered in the related studies carried out in other countries. Some of these factors are the occupations of parents and the type of school. For example, the learning patterns of children in families with unemployed mothers are generally different from those with employed mothers, as the time available for paying attention on children's education seems to matter a lot. A few studies have been conducted in Sri Lanka to identify the behavior of private tuition expenditure along with their influential factors (e.g. Madusankha, Ubesena, Lorensuhewa, Samaranayake, \& Hapuarachchi, 2015). However, these studies have been limited to descriptive analyses and the sample sizes had not been adequate. Therefore, investigation of socio-economic factors affecting $A / L$ tuition expenditure, with empirical evidence drawn from a reasonably large sample would significantly contribute to the literature.
Evidence can be found for the factors affecting education expenditure from countries such as Sudan (Ebaidalla, 2018), Malaysia (Jelani \& Tan, 2012), and Vietnam (Huy, 2012). Household income, level of household head's education, level of schooling are the key factors identified in many of the prior studies. Besides, the factors such as ethnicity, marital status, household head's age, household size, number of school-age children, and residing in urban areas have been found in earlier studies (Ebaidalla, 2018; Jelani \& Tan, 2012). The positive impact of household income and the level of education of the head of household on education expenditure has mostly been evident in developing countries. According to Ebaidalla (2018), households with higher income, whose heads are educated, and who reside in urban areas tend to spend more on education compared to poor and rural households in Sudan. Providing supporting evidence from Vietnam, Huy (2012) confirmed that families with college-age children spend more on education compared to those with pre-school-age children. In a study conducted in a multi-national developing community, Penang Malaysia, households of Chinese and Indian descent are more likely to send their children to private tuition (Jelani \& Tan, 2012). In addition to the key factors such as household income, level of household head's education, and level of schooling, the above reviews of literature justify the importance of considering context-specific factors when investigating the education expenditure of a country.

In a study, Pallegedara (2012) investigated the factors affecting the household budget share of private tuition in Sri Lanka. He examined the effect of household characteristics such as household income, level of parental education, the number of school-aged children, the number of adults, ethnicity, area of living (rural/urban), and gender (through comparison between households with only girls or boys). The findings of this study indicated that income, parents' education, the number of school-aged children in a family leads to increasing the budget share of private tuition classes. Besides, ethnicity and area of living had a significant impact on tuition expenditure.

Concerning private tuition in Sri Lanka, A/L classes have attracted greater attention than all other classes due to increasing competition for university entrance based on the performance in the G.C.E. A/L examination. However, no study focusing particularly on Sri Lankan A/L students' tuition expenditure was found in the literature. Furthermore, the demand for private tuition can be largely varied across subject streams (Arts/Commerce/Bio-Science/Physical Science/Technology) of G.C.E. Advanced Level (Bray \& Kwo, 2014; Pallegedara, 2012). Therefore, studying the differences in tuition expenditure based on the stream will provide valuable implications to education authorities as well as to the general public whereas there is no empirical evidence currently available.

In summary, this study identifies the lack of empirical evidence drawn from a large sample for the socio-economic factors affecting the household expenditure on tuition for advanced level students in Sri Lanka as a significant gap in the literature. Currently available research on tuition education in Sri Lanka have addressed areas such as demand for private tuition (Pallegedara, 2012), the impact (Madusankha, Ubesena, Lorensuhewa, Samaranayake, \& Hapuarachchi, 2015), and the issues associated (Foondun, 2002). The potential influential factors of tuition expenditure may include subject or school related factors as well as family specific factors. As there was no prior investigation on 
varied effects of these factors, it is also important to evaluate the magnitude of the effects of socio-economic factors on advanced level tuition expenditure in Sri Lanka.

\section{MATERIALS \& METHODS}

Based on the above reviews of literature, several hypotheses were developed to address the main research question of the study i.e. what are the key socio-economic factors that are directly influencing monthly household expenditure on private tuition for $\mathrm{A} / \mathrm{L}$ students in Sri Lanka? Accordingly, the following specific socio-economic factors were examined in this study:

- Subject stream (Arts, Biological Science, Commerce, Physical Science, and Technology)

- School category (national and other schools)

- Parents' education level (the highest education level of mother or father)

- Monthly household income

- Private tuition class category (individual classes, group classes, and hall classes)

- Total number of tuition class hours per month

- Number of students in the family

- Total monthly expenditure of the family.

The effect of each factor on monthly expenditure on private tuition classes was tested using multiple linear regression analysis. The multiple linear regression model is in the following form:

$$
E\left(Y_{i} \mid X_{1 i}, X_{2 i}, \ldots, X_{p i}\right)=\beta_{0}+\sum_{j=1}^{p} \beta_{j} X_{j i}
$$

where $Y_{i}$ is the monthly tuition expenditure of the $i^{\text {th }}$ student and $X_{j i}$ is the magnitude of the $j^{\text {th }}$ variable for the $i^{\text {th }}$ student. Dummy variables were used appropriately to represent the categorical variables such as $A / L$ subject stream and the school type. Any $\beta_{j}$ coefficient that significantly differs from zero implies that the variable $X_{j}$ is a determinant of monthly tuition expenditure for G.C.E. (A/L) students.

Embilipitiya educational zone of Rathnapura district in Sabaragamuwa province of Sri Lanka consists of 13 schools including two national schools. 1160 students were expecting to sit for the G.C.E. (A/L) examination in the year 2019 (Education Report of Embilipitiya Zone for 2018). Seven of these schools were categorized under the $1 A B$ category and the remaining six belonged to the category $1 \mathrm{C}$. The composition of the population of $2019 \mathrm{~A} / \mathrm{L}$ students in Embilipitiya education zone according to their subject stream is given in Table 1.

Table 1: Subject streams of 2019 G.C.E. (A/L) students in Embilipitiya education zone

\begin{tabular}{lr}
\hline Subject stream & Number of students (\%) \\
\hline Arts & $560(48.3 \%)$ \\
Biological Science & $267(23.0 \%)$ \\
Commerce & $190(16.4 \%)$ \\
Physical Science & $46(4.0 \%)$ \\
Technology & $97(8.4 \%)$ \\
\hline
\end{tabular}

Source: Education Report of Embilipitiya Zone for 2018

A stratified random sample of 200 students from the above population of 1160 students (17.2\%) was selected. The sample size for each stratum was calculated proportionately to the stratum size (probability proportional sampling). A selfadministered structured questionnaire was used to collect data.
The symmetry of the distribution of each continuous variable was graphically examined using histograms. The variables: monthly household income, the total monthly expenditure of household, the total number of tuition hours per month, and the monthly expenditure on tuition classes were identified as positively skewed variables. Expecting a high goodness-of-fit in the final multiple linear regression model, the log transformation was applied to the above variables. In the preliminary analysis, the statistical significance of the effect of each variable on monthly tuition expenditure was tested without adjusting for the effect of other socio-economic factors considered. The variables that indicated significant relationships with the log-transformed monthly tuition expenditure were only used in the final analysis. A multiple linear regression model was fitted to identify the significant explanatory variables that affect the response variable (the log-transformed monthly tuition expenditure).

\section{RESULTS AND DISCUSSION}

The descriptive statistical analysis showed that $25 \%$ of students are spending less than Rs. 9,000 per month on private tuition while another $25 \%$ of students are spending more than Rs. 13,500. The median monthly expenditure on tuition classes is Rs. 11,400 . The distribution of log-transformed monthly expenditure on tuition classes was approximately symmetric. The back-transformed mean (median) monthly expenditure on tuition classes is Rs. 11,702. The analysis on monthly tuition expenditure was carried out in two steps:

1. Examine the variations of monthly tuition expenditure considering one socio-economic variable at a time. In this analysis, the effect of the selected variable was discussed without adjusting to the effects of other variables.

2. Examine the variations of monthly tuition expenditure considering all the variables at the same time. The advantage of this method is that the effect of each variable can be discussed while adjusting for the effects of the other variables in the final model.

The variations of the monthly tuition expenditure due to individual socio-economic factors:

The subject streamwise distributions of the log-transformed monthly tuition expenditures are summarized using a Boxand-whisker plot in Figure 1. As there are concerns about the normality and homoscedasticity of the log-transformed variable, the Mood's median test was applied to test the equality of the median log-transformed monthly tuition expenditure across the five subject streams at a $5 \%$ level of significance. The $p$-value of the test $(0.000+)$ indicated that there are at least two medians that are significantly different.

The first two columns of Table 2 summarize the median and $95 \%$ confidence intervals of the streamwise log-transformed monthly tuition expenditures. These results are back-transformed in the last two columns of the table in order to interpret them in a meaningful way. The highest and the lowest median monthly tuition expenditures corresponding to Physical Science and Arts students were Rs.17,001 and Rs.9,149 respectively. Pairs of subject streams whose median monthly tuition expenditures are significantly different can be identified using none overlapping confidence intervals given in Table 2 . Accordingly, the median monthly tuition expenditure of the Arts stream significantly differs from that of the Biological Science, Physical Science, and Technology streams. The expenditure of subject streams, namely, 
Biological Science, Commerce, and Technology are significantly different from that of Physical Sciences. As it indicated in Figure 1 and Table 2, the monthly tuition expenditure of Biological Science is relatively consistent than all the other four subject streams. The variability of both Art and Commerce subject streams' monthly tuition expenditures is relatively high compared to that of the other three streams.

Figure 1: The stream wise distributions of the log-transformed monthly tuition expenditures

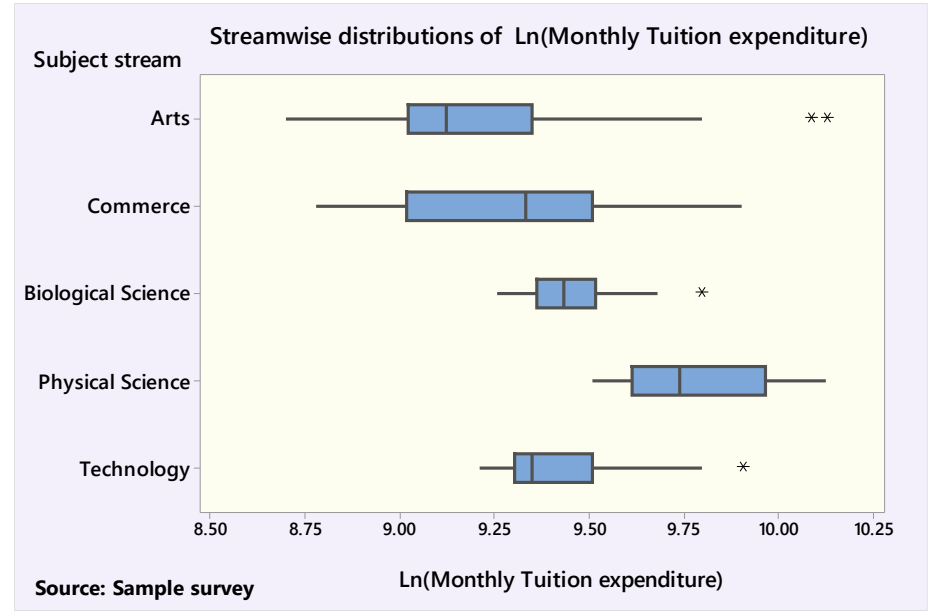

Table 2: Summary results of the log-transformed monthly tuition expenditures based on the subject stream

\begin{tabular}{|c|c|c|c|c|}
\hline \multirow[t]{2}{*}{ G.C.E. (A/L) Subject stream } & \multicolumn{2}{|c|}{ Ln (monthly tuition expenditure) } & \multicolumn{2}{|c|}{$\begin{array}{c}\text { Back transformed } \\
\text { Ln (monthly tuition expenditure) }\end{array}$} \\
\hline & Median & $95 \% \mathrm{Cl}$ & Median & $95 \% \mathrm{Cl}$ \\
\hline Arts & 9.1214 & {$[9.0825,9.1799]$} & 9149 & {$[8800,9700]$} \\
\hline Biological Science & 9.4335 & {$[9.3927,9.4758]$} & 12500 & {$[12000,13040]$} \\
\hline Commerce & 9.3326 & {$[9.1642,9.9427]$} & 11300 & {$[9549,20800]$} \\
\hline Physical Science & 9.7410 & {$[9.969,10.0281]$} & 17001 & {$[21354,22654]$} \\
\hline Technology & 9.3501 & {$[9.3057,9.4718]$} & 11500 & {$[11001,12988]$} \\
\hline
\end{tabular}

Source: Sample survey

The log-transformed monthly tuition expenditures exhibited a high degree of symmetry in their schoolwise (national schools and other schools) distributions. The pooled t-test was applied to test the equality of the mean log-transformed monthly tuition expenditures between two school types at a $5 \%$ level of significance. The $p$-value of 0.034 indicated a significant difference between the means. As this result implies, on average national schools' advanced level students spend Rs. 11415 on private tuition while other school students' average spending is Rs. 10421.

At least one parent of each family in the sample had either G.C.E. (Ordinary Level) or G.C.E. (Advanced Level) qualification. The higher education qualification of either mother or father was considered as the education level of the family. $59 \%$ of the families had G.C.E. (Advanced Level) qualification while the others having G.C.E. (Ordinary Level) qualification. The equality of the mean log-transformed monthly tuition expenditures between the families having G.C.E. (O/L) and G.C.E. $(A / L)$ qualification was tested using the pooled t-test after verifying the normality and the homoscedasticity assumptions. The small $p$-value $(0.000+)$ revealed that the mean log-transformed monthly tuition expenditures between the families having G.C.E. (O/L) and G.C.E. (A/L) qualifications are significantly different at a $5 \%$ level of signifi- cance. The families with parents having G.C.E. (A/L) qualification are spending Rs. 12620 on average on private tuition while other families' average spending is Rs. 9173 . It is quite interesting to find that more educated [G.C.E. (A/L)] families tend to spend more than less educated [G.C.E. (O/L)] families. There may be two possible explanations for this difference. Either these more educated families have a higher income than the other group or they expect more education for their children than the other group.

The type of tuition class is another important factor that can affect the monthly tuition expenditure of G.C.E. (A/L) students. The types of classes considered in this study are individual classes, group classes, hall classes, and a combination of group and hall classes. Usually, the cost of individual classes is relatively high. The monthly payment of group classes is also high, but it is shared among the members of the group. The size of a group can be varied normally between three and six students. Hall classes are conducted with large numbers of students. The size of a hall class can vary even up to thousand students depending on the popularity of the teacher. However, the cost of a hall class is relatively the lowest. 
Figure 2: Distributions of log-transformed monthly tuition expenditure based on the type of class

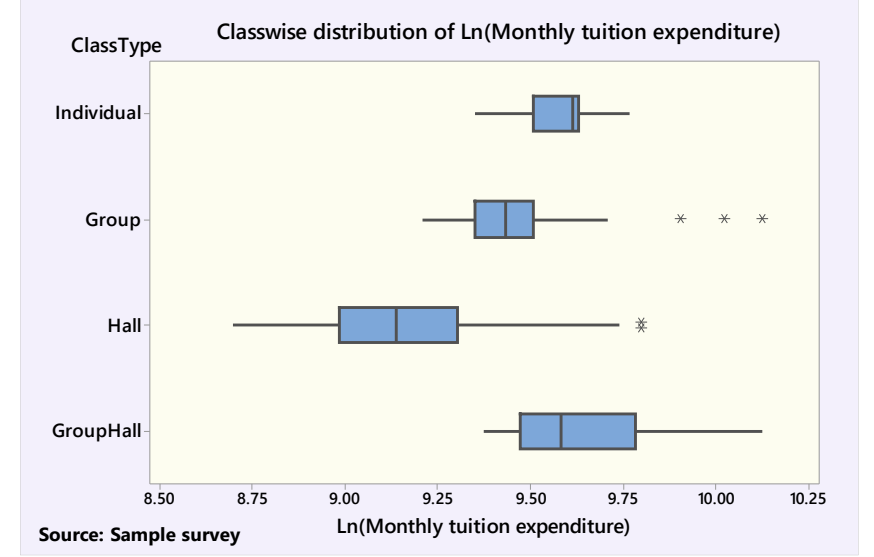

The percentages of students who get the service of individual classes, group classes, and hall classes are $10.5 \%, 21.5 \%$, and $57.5 \%$ respectively. Another $10.5 \%$ of the students are obtaining the service from both group and hall classes simultaneously. As it expected and shown in Table 3, the minimum (Rs. 9300) and maximum (Rs. 15000) monthly tuition expenditures are for hall classes and individual classes respectively. According to Figure 2, the monthly tuition expenditure on both Individual classes and Group classes is less variable than the other two types of classes. In addition, as it indicated by Figure 2, there were concerns about the validity of the assumptions of normality and homoscedastic-

test the equality of the median log-transformed monthly tuition expenditures among these four types of classes. The $p-$ value of the test was $0.000+$ and the test indicated the presence of at least one pair of class types whose median logtransformed monthly tuition expenditures are different at a $5 \%$ level of significance. Non-overlapping confidence intervals in Table 3 show the pairs of class types whose median monthly tuition expenditures are significantly different. Accordingly, the median monthly expenditures of hall classes and group classes are significantly different from that of the other three class types.

ity of the error terms of the one-way analysis of variance model. Therefore, the Mood's median test was applied to

Table 3: Summary results of log-transformed monthly tuition expenditure based on the type of tuition class

\begin{tabular}{|c|c|c|c|c|}
\hline \multirow[t]{2}{*}{ Type of class } & \multicolumn{2}{|c|}{ Ln(monthly tuition expenditure) } & \multicolumn{2}{|c|}{$\begin{array}{c}\text { Back transformed } \\
\text { Ln(monthly tuition expenditure) }\end{array}$} \\
\hline & Median & $95 \% \mathrm{Cl}$ & Median & $95 \% \mathrm{Cl}$ \\
\hline Individual & 9.6158 & {$[9.5104,9.6158]$} & 15000 & {$[13499,15000]$} \\
\hline Group & 9.4335 & {$[9.3718,9.4727]$} & 12500 & {$[11752,13000]$} \\
\hline Hall & 9.1378 & {$[9.0825,9.1639]$} & 9300 & {$[8800,9546]$} \\
\hline Group and hall & 9.5819 & {$[9.4727,9.7505]$} & 14500 & {$[13000,17163]$} \\
\hline
\end{tabular}

Source: Sample survey

The number of siblings in a family may also be a potential factor that could have a negative effect on monthly expenditures on private tuition classes. There were $10 \%, 51 \%$, and $32.5 \%$ of the families with one, two, and three children respectively. Only $6.5 \%$ of the families had four or more children. There were strong concerns about the homoscedasticity of the log-transformed monthly tuition expenditures. Therefore, the Moods' median test was applied at a $5 \%$ level of significance to test the equality among medians of the log-transformed monthly tuition expenditure. The result of

the test provided a $p$-value of 0.014 . Table 4 summarizes the medians and $95 \%$ confidence intervals of both log-transformed monthly tuition expenditures and the respective back-transformed values. As shown in Table 4, there is no substantial difference found in the monthly tuition expenditure when there are one, two, or three siblings in a family. However, when there are four or more siblings, the median monthly tuition expenditure is substantially low by around Rs. 3000 , and different from other families.

Table 4: Summary results of the log-transformed monthly tuition expenditures based on the number of siblings in the family

\begin{tabular}{lrrrr}
\hline \begin{tabular}{l} 
Number of $\begin{array}{l}\text { Liblings in } \\
\text { the family }\end{array}$ \\
\cline { 2 - 4 }
\end{tabular} & \multicolumn{2}{c}{ Median } & \multicolumn{2}{c}{$\begin{array}{l}\text { Back transformed } \\
\text { Ln (monthly tuition expenditure) }\end{array}$} \\
\hline One & 9.3057 & {$[9.2103,9.4635]$} & 11001 & $95 \% \mathrm{Cl}$ \\
Two & 9.3587 & {$[9.2591,9.4070]$} & 11599 & {$[10000,12881]$} \\
Three & 9.3501 & {$[9.3057,9.3759]$} & 11500 & {$[10500,12173]$} \\
Four or more & 9.024 & {$[8.8227,9.0240]$} & 8300 & {$[11001,11801]$} \\
\hline
\end{tabular}

Source: Sample survey

The number of siblings who are currently engaged in any sort of study is also an informative factor to be considered in a study on private tuition expenditures. There were $25.5 \%$ of the families that do not have any other children studying currently other than the child considered in this study. However, there are $55 \%$ and $19.5 \%$ of the families having one and two other children respectively who are currently studying. The one-way ANOVA model was applied to test the equality of the means of log-transformed monthly tuition 
expenditures across families with other numbers of siblings who are still studying. The test gave an insignificant $p$-value (0.767). Therefore, the mean monthly tuition expenditure is not dependent on the number of siblings in the family who are still studying. The study did not observe any significant difference in monthly tuition expenditures when there are up to three children in a family. Besides, there were no families in the sample that have more than two other children who are currently studying.

Employment of the parents is another potential factor that can have an impact on the monthly expenditure on private tuition of G.C.E. (A/L) students. All fathers in this study were employed as expected. However, only $58.5 \%$ of the mothers were employed. Therefore, family employment consisted of only two categories: only the father is employed and both Table 5: Summary results of the log-transformed monthly tuition expenditure based on the employment status of the family

\begin{tabular}{|c|c|c|c|c|}
\hline \multirow[t]{2}{*}{ Family employment status } & \multicolumn{2}{|c|}{ Ln(monthly tuition expenditure) } & \multicolumn{2}{|c|}{$\begin{array}{c}\text { Back transformed } \\
\text { Ln(monthly tuition expenditure) }\end{array}$} \\
\hline & Mean & $95 \% \mathrm{Cl}$ & Median & $95 \% \mathrm{Cl}$ \\
\hline Both & 9.4046 & {$[9.3573,9.4518]$} & 12144 & {$[11583,12731]$} \\
\hline Father only & 9.1819 & {$[9.1214,9.2424]$} & 9720 & {$[9149,10326]$} \\
\hline
\end{tabular}

Source: Sample survey

Family income, family expenditure, total number of hours that a student attending private tuition class per month (four weeks), total number of hours that a student is spending on sources of education other than school and private tuition (library, internet, books, educational newspapers, etc.), and the total number of hours per month that parents are spending on G.C.E. (A/L) students' education were the continuous explanatory variables considered in this study. parents are employed. The effect of family employment was tested using the pooled t-test and it produced a p-value of $0.000+$. As shown in Table 5, families that both parents are employed spend more on private tuition than the families that only the father is employed. The difference between them is statistically significant at a $5 \%$ level of significance. Therefore, the employment of mother in addition to the father's employment is a key factor that affects the private tuition expenditure. The $95 \%$ tail symmetric confidence interval for the difference between means of the log-transformed monthly tuition expenditures was [0.1474, 0.2980]. This confidence interval indicates with a $95 \%$ certainty that the mother's employment, in addition to the father's employment, increases the median monthly tuition expenditure by between $15.9 \%$ and $34.7 \%$.
As it observed in the analysis, monthly income, monthly expenditure, and the total number of tuition hours are positively skewed variables, hence, the log transformation was applied to obtain symmetric behaviors in these variables. Figure 3 illustrates the relationships of monthly tuition expenditures and $\operatorname{Ln}$ (Monthly tuition expenditures) with these factors.

Figure 3: The relationships of monthly tuition expenditures and Ln (Monthly tuition expenditures) with monthly income, monthly expenditure, the total number of tuition hours

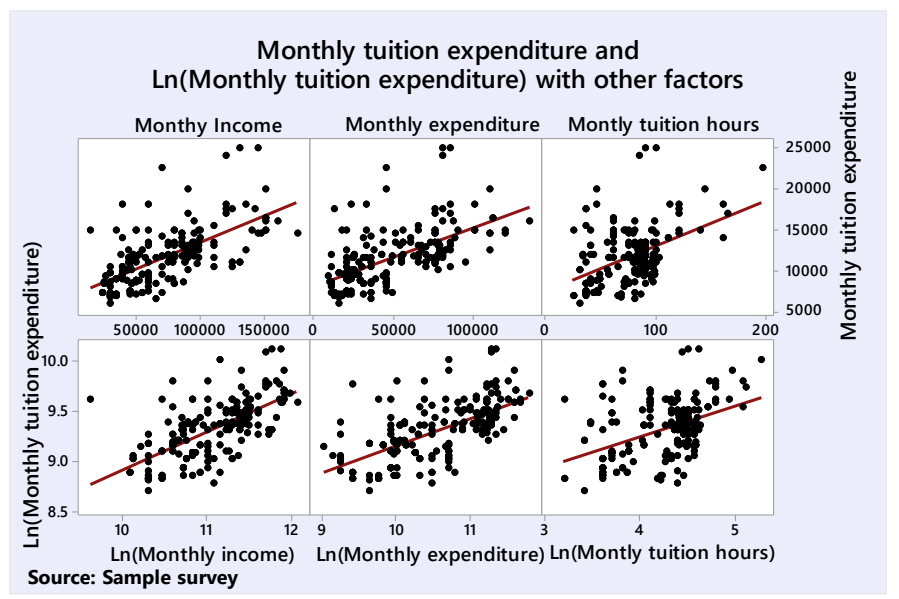

The graph indicates positive relationships of monthly tuition expenditures and Ln(monthly tuition expenditures) with all three variables. However, the total number of hours that a student spends on sources of education other than school and private tuition, and the total number of hours per

Table 6: Pearson's correlation coefficients and coefficients of determination (R2)

\begin{tabular}{lcr}
\hline Variable & \multicolumn{2}{c}{ Correlation coefficients, $\mathbf{p}$-values, and $\mathbf{R}^{\mathbf{2}}$} \\
\cline { 2 - 3 } & \multicolumn{1}{c}{ Class expenditure } & \multicolumn{1}{c}{ Ln(Class expenditure) } \\
\hline Income & $0.650(0.000+)(42.3 \%)$ & $0.663(0.000+)(44.0 \%)$ \\
Expenditure & $0.602(0.000+)(36.2 \%)$ & $0.635(0.000+)(40.4 \%)$ \\
Tuition hours & $0.454(0.000+)(20.6 \%)$ & $0.474(0.000+)(22.5 \%)$ \\
Extra sources hours & $0.051(0.477)(0.3 \%)$ & $0.070(0.323)(0.5 \%)$ \\
Parent hours & $0.297(0.000+)(8.9 \%)$ & $0.317(0.000+)(10.0 \%)$
\end{tabular}




$\begin{array}{ll}\text { Ln(Income) } & 0.625(0.000+)(39.1 \%) \\ \text { Ln(Expenditure) } & 0.583(0.000+)(34.0 \%) \\ \text { Ln(Tuition hours) } & 0.411(0.000+)(16.9 \%)\end{array}$

$0.653(0.000+)(42.6 \%)$

Source: Sample survey

As shown in Table 6, income, expenditure, Ln(income), and Ln(expenditure) are strongly positively related to both monthly tuition expenditure and their logarithmic values. According to the $\mathrm{R}^{2}$ values, more than one-third of the variation in private tuition expenditure and their logarithmic values are individually explained by income, expenditure, Ln(income), and Ln(expenditure). Tuition hours and their logarithmic values are relatively weakly related to both monthly tuition expenditure and their logarithmic values.

Variations of monthly tuition expenditures considering all significant variables:

Even though a majority of the socio-economic factors show significant effect on monthly tuition expenditure (or its logarithmic value) in the simple linear regression models fitted, many of them may not have a significant contribution in a model with all these significant factors. As logarithmic values of income and expenditure are highly correlated $(r=$ Table 7: Summary of the final model

\begin{tabular}{|c|c|c|c|}
\hline Term & Coefficient & $p$-value & VIF \\
\hline Constant & 6.550 & $0.000+$ & \\
\hline Ln(Income) & 0.153 & $0.000+$ & 1.88 \\
\hline Ln(Tuition) & 0.192 & $0.000+$ & 1.53 \\
\hline $\begin{array}{l}\text { Class type } \\
\text { (Reference = Hall classes }\end{array}$ & & & \\
\hline $\begin{array}{l}\text { Other } \\
\text { Stream } \\
\text { (Reference }=\text { Biological s }\end{array}$ & 0.334 & $0.000+$ & 1.94 \\
\hline Arts & 0.135 & $0.000+$ & 2.77 \\
\hline Commerce & 0.067 & 0.081 & 1.65 \\
\hline Physical & 0.414 & $0.000+$ & 1.17 \\
\hline Technology & 0.333 & $0.000+$ & 1.53 \\
\hline
\end{tabular}

Source: Sample survey

All the VIF values in Table 7 except that of Arts subject stream (2.77) are less than two indicating the absence of multicollinearity in the fitted model. More than $70 \%$ of the total variation in the monthly tuition expenditure on G.C.E. $(\mathrm{A} / \mathrm{L})$ can be explained using this model. According to Table 7, when the other factors are held constant, for every $1 \%$ increase in the monthly family income, the monthly tuition expenditure increases by about $0.153 \%$. For every $1 \%$ increase in the total monthly tuition hours, the monthly tuition expenditure increases by about $0.192 \%$. Compared to the students who spend only on hall classes, the students who attend individual classes or group classes averagely spend $39.7 \%$ on private tuition, holding other variables constant. Compared to Biological Science students, the students who are following Arts, Commerce, Physical Science, and Technology subjects averagely spend $14.5 \%, 6.9 \%, 51.3 \%$, and $39.5 \%$ respectively on G.C.E. (A/L) private tuition holding monthly income, total monthly class hours, and class type constant. As the $\mathrm{R}^{2}$ of the model was $69.1 \%$, this model
0.893), only one of them can be kept in the final model to avoid multicollinearity problems. Logarithmic values of income is more linearly related $(r=0.653)$ than logarithmic values of monthly expenditure ( $r=0.627)$ to logarithmic values of private tuition expenditure. Therefore, it was decided to keep logarithmic values of income in the final model. The final regression model was obtained as the best-fitted model with a coefficient of determination (Adjusted $\mathrm{R}^{2}$ ) of $70.9 \%$. The selected determinants of the model were:

- Logarithmic value of monthly family income - Ln( Income)

- Logarithmic value of monthly tuition hours - $\operatorname{Ln}$ (Tuition)

- Subject stream - Stream (Arts, Biology, Commerce, Physical, and Technology)

- Class type - Class (Hall and other classes) is found to be adequate for future predictions. As it shown in Figure 4, there are no concerns about the normality and homoscedasticity of the error terms in the regression model. The socio-economic factors identified in this study are somewhat similar to the observations in education systems in other developing countries. For instance, household income is a significant positive factor affecting education expenditure in Sudan (Ebaidalla, 2018) and Vietnam (Huy, 2012). This seems to continue the gap between rich and poor in these countries as the highly educated people have more ability to earn more income in the future as well. The two significant factors affecting tuition expenditure, class type and subject stream identified in this study imply the increased competition in the Sri Lankan education system. These findings align with the current literature (Pallegedara, 2012) that suggests the growing competition in Sri Lanka based on private tuition. 
Figure 4: Residual analysis of the fitted regression model of the $\operatorname{Ln}($ Monthly tuition expenditures)

\section{Residual analysis of the regression model}

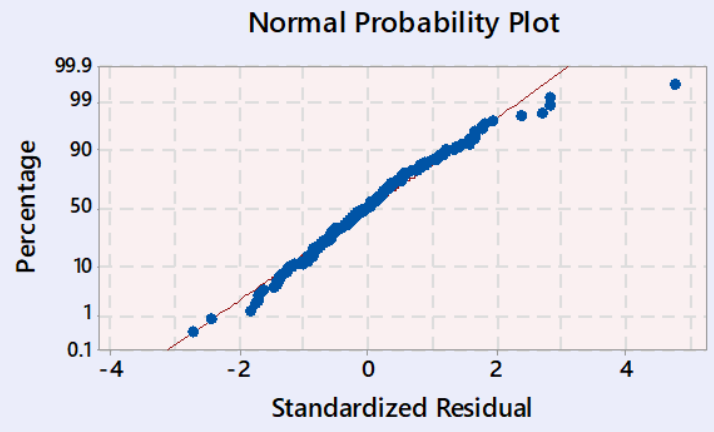

Histogram

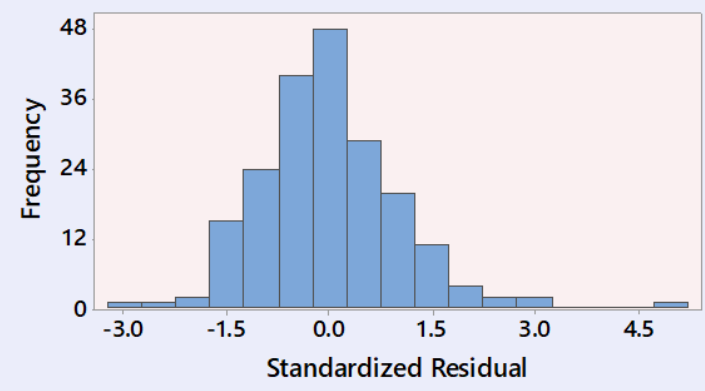

Source: Sample survey

\section{CONCLUSION AND IMPLICATIONS}

This study aimed to identify the determinants of the monthly private tuition expenditure of G.C.E. (A/L) students in the Embilipitiya educational zone in Sri Lanka. A stratified random sample of 200 out of 1160 students who were to sit for the A/L examination in 2019 in each subject stream: Arts, Biological Science, Commerce, Physical Science, and Technology in the Embilipitiya educational zone of Rathnapura district in Sri Lanka was selected for the study. Data gathered using a structured questionnaire were analyzed using multiple linear regression modeling with logarithmic transformation. Considering both the current literature and the Sri Lankan context related to the area of research, eleven factors, namely, household income, total household expenditure, total number of monthly tuition hours, parents' dedication to the student's education in terms of hours, student's commitment to gathering information using additional resources (library and internet, etc.), number of siblings in the family, subject stream (Arts, Biological Science, Commerce, Physical Science, and Technology), school type (national and others), family education background, the level of employability of parents, type of tuition classes (hall, group, and individual) were identified as the potential determinants of monthly tuition expenditure of Advanced Level students.

The magnitude of the effect of each socio-economic factor was initially evaluated using various statistical tests selected based on the type of variable (categorical or continuous). Finally, a multiple linear regression model was developed verifying all the relevant underlying assumptions. Monthly household income, the total number of monthly tuition hours, subject stream, and the type of tuition class were identified as the significant determinants of the monthly tuition expenditure of G.C.E. Advanced Level students in Ebilipitiya educational zone. The finalized model is capable to ex-
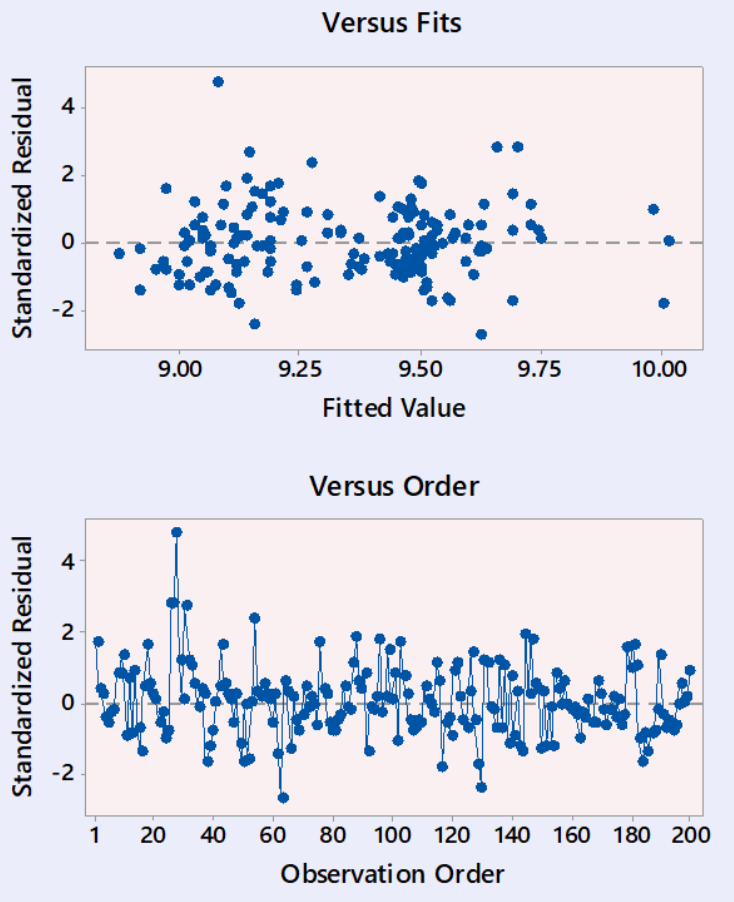

plain more than $70 \%$ of the variation in monthly tuition expenditure. The most significant contribution of this research is evaluating the magnitude of the effect of each factor studied. The results are very useful not only to identify the impact of socio-economic factors on monthly tuition expenditure but also to make predictions, as the explanatory power of the proposed model is reasonably high (more than 69\%). The patterns and relationships identified in this research are quite interesting and offer a range of important implications for educators and policymakers. The government schools and the ministry of education should pay immediate attention to the increasing trend of private tuition. These institutions need to be more market-oriented even though they are operating in the government sector. Understanding the unfulfilled needs of students as well as parents is a key to make new plans. However, if the customer needs are not well addressed, then it and hinder the country's development in terms of people's creativity, innovativeness, financial management, and stability. Therefore, suitable steps should be taken strategically. For example, increasing salaries and benefits given to school teachers and introducing new programs to improve the quality of school education would make a significant difference. For the success of such programs, it would be worthwhile to study the feasibility of getting a small financial contribution from parents upon their consent and utilizing that money for developing the level of education service of schools. However, implementing such plans will be challenging in a country like Sri Lanka due to many social and economic reasons. Therefore, this needs to be properly planned and carefully analyzed in advance.

This research addresses an extremely important area of tuition education in Sri Lanka on which currently available knowledge is limited. The findings of this research addressing the socio-economic factors affecting the household expenditure on advanced level tuition are original as the available literature are mainly focused on the issues, demand, 
and impact of private tuition education in Sri Lanka. The contribution of the study to theory is significant as the socioeconomic factors identified in this research represent unique context of Sri Lankan tuition education and hence extends the currently available literature on similar investigations conducted in other countries such as Sudan (Ebaidalla, 2018) and Vietnam (Huy, 2012). Supporting the available literature, this research has also identified household income as a significant determinant of educational expenditure.

\section{REFERENCES}

Bray, Mark, \& Kwo, Ora. (2014). Regulating private tutoring for public good. Policy Options for Supplementary Education in Asia. UNESCO Bangkok.

Bray, Mark, \& Lykins, Chad. (2012). Shadow education: Private supplementary tutoring and its implications for policy makers in Asia: Asian Development Bank.

Cole, Rachel. (2016). How Free is Free Education?: Educational Stratification in Sri Lanka: 1985-2010. from https://groundviews.org/2015/02/08/how-free-is-free-educationeducational-stratification-in-sri-lanka-1985-2010/

Ebaidalla, Ebaidalla M. (2018). Understanding household education expenditure in Sudan: do poor and rural households spend less on education? African Journal of Economic Review, 6(1), 160-178.

Education Report of Embilipitiya Zone for 2018 (2018).

Educational Social Science Foundation. (1989).

Foondun, A Raffick. (2002). The issue of private tuition: An analysis of the practice in Mauritius and selected South-East Asian countries. International review of Education, 48(6), 485-515.

Huy, Vu Quang. (2012). Determinants of educational expenditure in Vietnam. International Journal of Applied Economics, 9(1), 59-72.

Jelani, Juliana, \& Tan, Andrew KG. (2012). Determinants of participation and expenditure patterns of private tuition received by primary school students in Penang, Malaysia: An exploratory study. Asia Pacific Journal of Education, 32(1), 35-51.

Madusankha, A.A.M, Ubesena, M.D.M., Lorensuhewa, L.L.R., Samaranayake, U.G.P.S., \& Hapuarachchi, H.T.A.S. (2015). The Impact of Tuition Classes n University Entrance. Journal social statistics.

National Education Research and Evaluation Center (2004)

Pallegedara, Asankha. (2012). Demand for private tutoring in a free education country. The case of Sri Lanka. International Journal of Education Economics and Development, 3(4), 375-393.

Sri Lanka Education Reports. (2007). Maharagama: National Institute of Education. 
